\title{
PREDICTIVE SIGNIFICANCE OF THE LIFE HISTORY OF CHILDREN WITH GASTROESOPHAGEAL REFLUX FOR PREDICTING THE DEVELOPMENT OF ARRHYTHMIAS AND CONDUCTION DISORDERS
}

\author{
Oksana Herasymova \\ Department of Pediatrics and Pediatric Cardiorheumatology \\ Kharkiv Medical Academy of Postgraduate Education \\ 58 Amosova str., Kharkiv, Ukraine, 61176 \\ oleksiisenik@ukr.net
}

\begin{abstract}
Abstratc
The aim: to improve the early diagnosis of cardiac arrhythmias and conduction disorders in children with gastroesophageal reflux, by studying the prognostic significance of the life history in this group of patients.

Materials and methods. 56 children aged 8 to 18 years, mean age $14.93 \pm 2.62$ years were examined. All examined children were divided into two alternative groups: Group I (main) was represented by 28 children with gastroesophageal reflux in combination with cardiac arrhythmias and conduction disorders, and Group II (control) - 28 children with only gastroesophageal reflux without cardiac arrhythmias and conduction disorders. Patients underwent clinical, anamnestic (with a detailed study of life history) and instrumental studies (electrocardiography, Holter daily ECG monitoring, esophagogastroduodenoscopy).

Results. When analyzing the prognostic significance of the patient's life history, it was found that its very high level was observed for the number of foci of chronic infection $(I=6.0)$ and the frequent incidence of a child up to year old of life $(I=3.05)$.

High prognostic value was registered relative to the number of diseases suffered by the child per year on average $(I=2.35)$, and moderate predictor properties are characteristic of chickenpox $(I=0.89)$ and the number of chronic diseases at present $(I=0.71)$.

The duration of breastfeeding showed low $(I=0.30)$ prognostic significance.

Suffered previously bacterial infections did not have predictor properties $(I=0.12)$. In general, the prognostic significance of the patient's life history was high $(\overline{\mathrm{I}}=2.20)$.

Conclusions. It was found that in general the prognostic significance of the patient's life history was high $(\overline{\mathrm{I}}=2.20)$.

It is determined that in favour of the development of cardiac arrhythmias and conduction disorders evidence: the number of foci of chronic infection $\geq 1-2$; lack of frequent morbidity in a child up to a year of life; the number of diseases suffered per year $\leq 5$; the presence in past medical history of chickenpox; the number of chronic diseases in a child at present $\leq 2$ and shortterm ( $\leq 9$ months) breastfeeding.

It has been established what denies probability of development of the researched pathology: absence of the centers of a chronic infection; the presence frequent incidence of a child up to year old of life; the number of diseases suffered per year $\geq 6$, and chronic diseases at present $\geq 3$; longer ( $\geq 9$ months) breastfeeding and no history of chickenpox.
\end{abstract}

Keywords: prognostic significance, gastroesophageal reflux, arrhythmias, life history, children.

DOI: $10.21303 / 2504-5679.2021 .002194$

\section{Introduction}

There is an increase in heart rhythm and conduction disorders all over the world. Their share among all diseases of the cardiovascular system according to various scientists is up to $30 \%$ [1]. For example, the prevalence of this type of heart rhythm disorder, such as atrial fibrillation over the past 50 years has increased 3 times worldwide $[2,3]$.

Diagnosis of arrhythmias and cardiac conduction disorders in children causes many difficulties, because in this group of patients this pathology often has an asymptomatic course or its symptoms are disguised as symptoms of other diseases $[4,5]$. These difficulties lead to late diagnosis of this pathological process, which in turn provokes more severe forms of its course, a large number of dangerous complications, frequent chronicity and increased risk of sudden death [6, 7].

An even more difficult task is to conduct in children the differential diagnosis of arrhythmias and conduction disorders of the heart in combination with gastro-oesophageal reflux disease (GERD) with other pathologies [8, 9]. The reasons for this are that some digestive diseases 
that are accompanied by GERD (chronic gastroduodenitis) often have an erased clinical picture with asymptomatic manifestations [10, 11]. At the same time, atypical cardiac clinical forms are widespread among the second part of similar diseases (gastroesophageal reflux disease); the symptom complex of which has many symptoms in common with the symptom complex of arrhythmias and conduction disorders $[12,13]$. Differential diagnosis of isolated forms of arrhythmias and cardiac conduction disorders in children with their forms in combination with GERD is also complicated.

An analysis of the scientific literature revealed that scientists have identified many different predictors for different types of arrhythmias and conduction of the heart in children [14]. For example, risk factors for some of the most common types of arrhythmias (atrial fibrillation and ventricular tachycardia) are markers of systemic inflammation, such as: C-reactive protein, fibrinogen and certain interleukins (IL-1, IL-2, IL-6, IL-8) [15, 16].

Predictors of arrhythmias and conduction disturbances in combination with some concomitant pathologies, in particular type 1 diabetes mellitus and fatty liver disease, have also been identified [17, 18].

However, the prognostic significance of life history in the occurrence of a combination of cardiac arrhythmias and conduction in children with concomitant GERD is insufficiently studied. Therefore, determining the predictor properties of life history in relation to the development of this pathology in children will diagnose it in the early stages before the onset of severe complications. It will also help clinicians in making a differential diagnosis between it and isolated forms of arrhythmias and conduction disorders and diseases of the digestive system, accompanied by GERD (gastroesophageal reflux disease and chronic gastroduodenitis). This work is devoted to the study of these issues.

The aim of the work was to improve the early diagnosis of cardiac arrhythmias and conduction in children with GER, by studying the prognostic significance of life history in this group of patients.

\section{Materials and methods}

We examined 56 children aged 8 to 18 years, mean age $14.93 \pm 2.62$ years, who were hospitalized on the basis of the city cardiorheumatology department of «Children's Clinical Hospital No. 24» of the Kharkiv City Council and dispensary supervision in «City children's polyclinic No. 23» of the Kharkiv City Council in the period from September 2018 to July 2021. All examined children were divided into two alternative groups: Group I (main) was represented by 28 children with GERD in combination with cardiac arrhythmias and conduction, and Group II (control) 28 children with only GERD without cardiac arrhythmias and conduction.

The distribution by sex was homogeneous in both groups: in group I - the number of boys was $18(64.3 \pm 9.1) \%$, and girls - $10(35.7 \pm 9.1) \%\left(\chi^{2}=0.571 ; p=0.4497>0.05\right)$; in group II $12(42.9 \pm 9.4) \%$ of boys and $16(57.1 \pm 9.4) \%$ of girls, respectively $\left(\chi^{2}=2.286 ; p=0.1306>0.05\right)$.

During the study, the principles of the Declaration of Helsinki adopted by the General Assembly of the World Medical Association (1964-2000) and the protocol of the Bioethics Commission of the Kharkiv Medical Academy of Postgraduate Education No. 4 dated 18.11.2021 were followed. Informed consent was obtained from all parents or guardians of the children who participated in the study.

Criteria for inclusion in the study included:

1) the presence of GERD in combination with cardiac arrhythmias and conduction or only GERD without cardiac arrhythmias and conduction,

2) the age of children from 8 to 18 years,

3) voluntary consent of parents or guardians to participate in the research.

Clinical trials were a survey of patients for the presence or absence of relevant complaints, which are characteristic of the studied pathology and their further detailing: to determine the nature, frequency, severity, duration, and number of identified complaints.

Anamnestic studies included a thorough study of perinatal, hereditary and life and disease history.

The basis for confirming the presence of GERD was the results of esophagogastroduodenoscopy.

Arrhythmias in children were verified using data obtained during electrocardiographic examination and Holter daily ECG monitoring with the Poly-spectrum DM device.

Exclusion criteria were: congenital heart disease; acute inflammatory processes during the examination; condition after correction of congenital heart disease or radiofrequency catheter 
ablation; severe somatic pathology in a state of decompensation and refusal of parents of children or guardians to participate in the study.

Statistical processing of the results was performed using a spreadsheet MS Office Excel (Microsoft Corporation, USA) and a statistical online calculator epitools (epitools.ausvet.com.au, Austria). The age of patients was estimated by determining the sample mean and its standard error. The prognostic significance of complaints was determined using a heterogeneous sequential Wald-Genkin procedure, by calculating prognostic factors (PF) and informativeness (I). The homogeneity of the groups by sex was checked on the basis of the criterion $\chi^{2}$ for one-dimensional frequency tables. All calculations were performed with a $95 \%$ confidence level.

\section{Results}

The study of the prognostic significance of the anamnesis of patients' lives established (Table 1), that its very high level was observed for the number of foci of chronic infection $(I=6.0)$ and the presence of frequent morbidity in a child under one year of age $(I=3.05)$.

Table 1

Prognostic significance of life history of patients for the development of cardiac arrhythmias and conduction in children with GERD

\begin{tabular}{|c|c|c|c|}
\hline Indicators & Gradation of the indicator & PF & I \\
\hline \multirow{3}{*}{ Number of foci of chronic infection } & 0 & -10.0 & \multirow{3}{*}{6.00} \\
\hline & 1 & +1.0 & \\
\hline & $\geq 2$ & +10.0 & \\
\hline \multirow{2}{*}{ Frequent morbidity of a child under one year of age } & absent & +5.1 & \multirow{2}{*}{3.05} \\
\hline & present & -5.8 & \\
\hline \multirow{3}{*}{ The number of diseases per year on average } & $\leq 2$ & +2.0 & \multirow{3}{*}{2.35} \\
\hline & $3-5$ & +3.8 & \\
\hline & $\geq 6$ & -5.6 & \\
\hline \multirow{2}{*}{ Varicella } & present & +3.4 & \multirow{2}{*}{0.89} \\
\hline & absent & -2.3 & \\
\hline \multirow{2}{*}{ The number of chronic diseases at present } & $\leq 2$ & +3.0 & \multirow{2}{*}{0.71} \\
\hline & $\geq 3$ & -2.0 & \\
\hline \multirow{2}{*}{ Duration of breastfeeding, months } & $\leq 9.0$ & +1.4 & \multirow{2}{*}{0.30} \\
\hline & $\geq 9.1$ & -2.0 & \\
\hline \multirow{2}{*}{ Bacterial infections } & present & -1.6 & \multirow{2}{*}{0.12} \\
\hline & absent & -0.4 & \\
\hline
\end{tabular}

Note: the sign (+) indicates the development of cardiac arrhythmias and conduction, and the sign (-) rejects the likelihood of their occurrence

High prognostic value was registered relative to the number of diseases transmitted by the child per year $(I=2.35)$, and moderate predictor properties are characteristic of chickenpox $(I=0.89)$ and the number of chronic diseases at present $(I=0.71)$.

The duration of breastfeeding showed low $(\mathrm{I}=0.30)$ prognostic significance.

Transferred bacterial infections did not have predictor properties $(\mathrm{I}=0.12)$.

In general, the prognostic significance of the patient's life history was high $(\overline{\mathrm{I}}=2.20)$.

\section{Discussion}

Although the analysis of the scientific literature did not reveal direct data on the impact on the occurrence of cardiac arrhythmias and conduction in children, we found predictors with very high (number of foci of chronic infection) and moderate prognostic value (chickenpox), but hypothetically indirect data that may confirm their significant role in the formation of this pathology are scientific sources, which have proven high predictor properties in the development of hereditary arrhythmias of such a clinical symptom as fever $[19,20]$. Due to the fact that this symptom is 
characteristic of the chickenpox clinic and can be accompanied by a chronic infection in the presence of a large number of its foci in the body. Regarding the information in the scientific literature on the prognostic significance of the absence of frequent morbidity of a child under one year of age, the number of diseases transmitted by a child per year and the number of chronic diseases currently for cardiac arrhythmias and conduction in children has not been found.

Also, no data were found on the predictor properties of life history in children with arrhythmias and cardiac conduction disorders in combination with concomitant GERD.

The practical significance of the results of the study is to develop criteria for early diagnosis and differential diagnosis of arrhythmias and cardiac conduction disorders in combination with concomitant GERD and isolated forms of this pathology and diseases of the digestive system, accompanied by GERD. The use of these criteria does not require any additional investment. However, it will not only improve the diagnostic process, but also reduce the material costs for the treatment of these pathologies, due to their course in milder forms; with a lower frequency of chronicity and the number of dangerous complications, especially the risk of sudden death.

Study limitations: a small sample of patients participated in the study.

Prospects for further research: conducting a study on a large sample of patients.

\section{Conclusions}

1. It was found that in general the prognostic significance of the patient's life history was high $(\overline{\mathrm{I}}=2.20)$.

2. It is determined that in favour of the development of cardiac arrhythmias and conduction indicate: the number of foci of chronic infection $\geq 1-2$; absence of frequent morbidity of a child under one year; the number of transferred diseases per year on average $\leq 5$; presence in the anamnesis of the transferred chickenpox; the number of chronic diseases in the child at present $\leq 2$ and short-term ( $\leq 9$ months) breastfeeding.

3. It is established that rejects probability of development of the considered pathology: absence of the centers of a chronic infection; the presence of frequent morbidity in children under one year; the number of transferred diseases per year $\geq 6$, and chronic diseases at present $\geq 3$; longer ( $\geq 9$ months) breastfeeding and no history of chickenpox.

\section{Conflict of interests}

The authors declare that they have no conflicts of interest.

\section{Financing}

The study was performed without financial support.

\section{Acknowledgments}

We are grateful to the patients who participated in the study, as well as to the specialists who made a significant contribution to the instrumental examination of patients.

\section{References}

[1] Senatorova, H. S., Honchar, M. O., Strashok, O. I., Khain, M. A., Strelkova, M. I. (2018). Takhiarytmii u ditei. Kharkiv: Novoe slovo, 84.

[2] Kornej, J., Börschel, C. S., Benjamin, E. J., Schnabel, R. B. (2020). Epidemiology of atrial fibrillation in the 21st century: novel methods and new insights. Circulation research, 127 (1), 4-20. doi: http://doi.org/10.1161/circresaha.120.316340

[3] Lippi, G., Sanchis-Gomar, F., Cervellin, G. (2020). Global epidemiology of atrial fibrillation: An increasing epidemic and public health challenge. International Journal of Stroke, 16 (2), 217-221. doi: http://doi.org/10.1177/1747493019897870

[4] Drago, F., Battipaglia, I., Di Mambro, C. (2018). Neonatal and pediatric arrhythmias: clinical and electrocardiographic aspects. Cardiac electrophysiology clinics, 10 (2), 397-412. doi: http://doi.org/10.1016/j.ccep.2018.02.008

[5] Rohit, M., Kasinadhuni, G. (2020). Management of Arrhythmias in Pediatric Emergency. The Indian Journal of Pediatrics, 87 (4), 295-304. doi: http://doi.org/10.1007/s12098-020-03267-2

[6] Osteraas, N. (2021). Neurologic complications of brady-arrhythmias. Handbook of Clinical Neurology. Elsevier, $177,163-174$. doi: http://doi.org/10.1016/b978-0-12-819814-8.00006-8 
[7] Aro, A. L., Chugh, S. S. (2017). Prevention of sudden cardiac death in children and young adults. Progress in Pediatric Cardiology, 45, 37-42. doi: http://doi.org/10.1016/j.ppedcard.2017.03.003

[8] Frieling, T. (2018). Non-Cardiac Chest Pain. Visceral Medicine, 34 (2), 92-96. doi: http://doi.org/10.1159/000486440

[9] Rees, C. J., Cantor, R. M., Pollack, Jr. C. V., Riese, V. G.; Pollack, Jr. C. (Ed.) (2019). Gastroesophageal Reflux Disease. Differential Diagnosis of Cardiopulmonary Disease. Cham: Springer, 441-449. doi: http://doi.org/10.1007/978-3-319-63895-9_30

[10] Korotkaya, Y., Shores, D. (2020). Helicobacter pylori in Pediatric Patients. Pediatrics in Review, 41 (11), 585-592. doi: http:// doi.org/10.1542/pir.2019-0048

[11] Iwańczak, B., Buchner, A., Iwańczak, F. (2017). Clinical differences of Helicobacter pylori infection in children. Advances in Clinical and Experimental Medicine, 26 (7), 1131-1136. doi: http://doi.org/10.17219/acem/60581

[12] Silvia, C., Serena, S., Chiara, M., Alberto, B., Antonio, N., Gioacchino, L., Francesco, D. M. (2018). Diagnosis of GERD in typical and atypical manifestations. Acta Bio Medica: Atenei Parmensis, 89 (Suppl 8), 33-39. doi: http://doi.org/10.23750/ abm.v89i8-S.7963

[13] Pandit, S., Boktor, M., Alexander, J. S., Becker, F., Morris, J. (2018). Gastroesophageal reflux disease: A clinical overview for primary care physicians. Pathophysiology, 25 (1), 1-11. doi: http://doi.org/10.1016/j.pathophys.2017.09.001

[14] Tomchik, N. V., Lyalikov, S. A., Suschevich, N. V. (2017). The prognostic model of arrhythmic syndrome on the basis of the results of clinical and instrumental studies in children with small heart anomalies. Meditsinskie novosti, 5, 57-60.

[15] Yalta, T., Yalta, K. (2017). Systemic Inflammation and Arrhythmogenesis: A Review of Mechanistic and Clinical Perspectives. Angiology, 69 (4), 288-296. doi: http://doi.org/10.1177/0003319717709380

[16] Vonderlin, N., Siebermair, J., Kaya, E., Köhler, M., Rassaf, T., Wakili, R. (2019). Critical inflammatory mechanisms underlying arrhythmias. Herz, 44 (2), 121-129. doi: http://doi.org/10.1007/s00059-019-4788-5

[17] Demyanenko, A. N., Alimova, I. L. (2019). Cardiac Autonomic Neuropathy and Hypoglycemia as Independent Predictors of QTc Elongation at Night in Adolescents With Type 1 Diabetes: Cohort Study. Current Pediatrics, 18 (4), 264-269. doi: http:// doi.org/10.15690/vsp.v18i4.2043

[18] Anstee, Q. M., Mantovani, A., Tilg, H., Targher, G. (2018). Risk of cardiomyopathy and cardiac arrhythmias in patients with nonalcoholic fatty liver disease. Nature Reviews Gastroenterology \& Hepatology, 15 (7), 425-439. doi: http://doi.org/10.1038/ s41575-018-0010-0

[19] Chuprova, S. N., Rudneva, E. P., Lobzin, Y. V. (2020). Inherited heart rhythm and conduction disorders in children with infectious diseases. Medical Council, 10, 126-133. doi: http://doi.org/10.21518/2079-701x-2020-10-126-133

[20] Chen, X., Zhao, H., Sun, L., Zhu, W., Zhang, F. (2020). Electrocardiogram Characteristics and Arrhythmic Events during Fever in Patients with Fever-Induced Brugada Syndrome. Cardiology, 145 (3), 130-135. doi: http://doi.org/10.1159/000505642

How to cite: Herasymova, O. (2021). Predictive significance of the life history of children with gastroesophageal reflux for predicting the development of arrhythmias and conduction disorders. EUREKA: Health Sciences, 6, 43-47. doi: http://doi.org/10.21303/ 2504-5679.2021.002194 